JISIP: Jurnal Ilmu Sosial dan Ilmu Politik

ISSN. 2442-6962

Vol. 9. No. 2 (2020)

\title{
PERAN MEDIA SOSIAL INSTAGRAM TERHADAP PUBLIKASI HASIL FOTOGRAFI UKM X-FLASH
}

\author{
Marcy Adingsih Djmailay ${ }^{1} \&$ Sulih Indra Dewi ${ }^{2}$ \\ ${ }^{1,2}$ Program Studi Ilmu Komunikasi, Universitas Tribhuwana Tunggadewi \\ Email : adiningsihmarcy@ gmail.com
}

\begin{abstract}
The purpose of the research is to find out and study the Instagram social media role in the publication of photography results of X-Flash student activity unit and photo publication on Instagram supporting the creativity of members. Technology advance nowadays make it easier for people to find out the needed information easily just by using the internet and what's new in the internet world is social media. One of the most popular social media today is Instagram with its advantages that it can beautify photos with various existing features, distribute photos and to market products or sell online. The existence of Instagram is used by those who have a hobby of photography to show their works. Therefore, this study aims to examine the role of Instagram social media on the publication of the X-Flash photography results. The data analysis technique used were data reduction, data presentation and verification. Based on the result of data analysis, it was found that the role of Instagram social media were as a media for publication and promotion to increase popularity, increase the existence of $X$-Flash, give or receive online invitation from off-campus photography communities and introduce the work of X-Flash to the public. There were ways to increase the creativity of members, namely by sharing, hunting together, holding exhibition and re-uploading members' work.
\end{abstract}

Keywords: Social Media Instagram, Instagram, Photography, UKM X-Flash

\begin{abstract}
Abstrak: Tujuan penelitian ini yaitu untuk mengetahui dan mempelajari peran media sosial instagram terhadap publikasi hasil fotografi UKM X-Flash serta publikasi foto di instagram yang mendukung kreativitas anggota. Kemajuan teknologi saat ini memudahkan masyarakat untuk mengetahui informasi yang dibutuhkan dengan mudah hanya dengan menggunakan internet dan yang baru di dunia insternet adalah media sosial. Salah satu media sosial yang terpopuler saat ini adalah instagram dengan kelebihannya yang bisa memperindah foto dengan berbagai fitur yang ada, menyebarkan foto dan untuk memasarkan produk atau berjualan online. Adanya instagram ini dimanfaatkan oleh mereka yang memiliki hobi dalam dunia fotografi untuk memperlihatkan hasil karyanya. Oleh karena itu, pada penelitian ini ingin meneliti peran media sosial instagram terhadap publikasi hasil fotografi UKM X-Flash. Teknik analisis data yang digunakan adalah reduksi data, penyajian data dan verifikasi. Berdasarkan hasil analisis data diperoleh peran media sosial instagram yaitu sebagai media publikasi dan promosi untuk meningkatkan popularitas, meningkatkan eksistensi UKM X-Flash, memberikan atau menerima undangan online dari komunitas fotografi luar kampus dan mengenalkan hasil karya UKM X-Flash kepada khalayak. Adapun cara untuk meningkatkan kreativitas anggota yaitu dengan melakukan sharing, hunting bersama, mengadakan pameran dan mengunggah kembali karya anggota.
\end{abstract}

Kata Kunci: Media Sosial, Instagram, Fotografi, UKM X-Flash

\section{Pendahuluan}

Media sosial Instagram memiliki kelebihan utama pada tampilan visual. Media yang didirikan pada 6 oktober 2010 oleh Kevin Systrom dan Mike Krieger diambil dari kata "instan" dan "telegram". Penggabungan ini memiliki arti bahwa Instagram adalah media sosial yang dapat menampilkan foto secara instan dan cepat (Nurudin, 2009). Dalam Instagram seseorang dapat menjadi pengikut atau 
JISIP: Jurnal Ilmu Sosial dan Ilmu Politik

ISSN. 2442-6962

Vol. 9. No. 2 (2020)

mengikuti akun instagram lainnya. Dengan cara inilah satu pengguna dengan pengguna yang lain dapat berkomunikasi yang bisa dilakukan dengan cara memberikan tanda suka, memberikan komentar pada foto-oto yang diunggah di beranda, atau dengan cara mengirim pesan langsung dalam kotak pesan yang dikenal dengan direct message.

Media sosial ini dapat digunakan sebagai tempat untuk menyalurkan hasil fotografi dan manfaat positif dalam menggunakan instagram yaitu bisa berbagi tentang sesuatu yang di peroleh di sekitarnya melalui sebuah foto, menuangkan ide kreatif melalu foto atau bisa sebagai media promosi dan informasi. Dari hal tersebut maka media sosial instagram mempunyai peranan penting dalam menerapkan hasil fotografi. Media sosial instagram memiliki peranan yang besar untuk mendukung hobi seseorang dalam dunia fotografi (Puntoadi, 2011). Peranan media sosial instagram menjadi sarana bagi seseorang untuk berkomunikasi atau berbagi aktivitas yang dilakukannya lewat sebuah foto, karena instagram dilengkapi dengan fitur-fitur yang menarik untuk mengedit foto.

Instagram juga telah berhasil mencuri perhatian generasi milenial, dimana dengan media sosial ini seseorang bisa berkomunikasi dengan orang terdekat, kenalan yang memiliki hobi yang sama dalam hal ini yaitu fotografi. Fotografi yang dilakukan untuk koleksi foto di instagram memiliki berbagai jenis foto yang menarik. Hal ini dilakukan untuk menarik perhatian orang lain atau pengikut di instagram. Tentunya seorang yang akan menghasilkan foto harus memiliki pengetahuan dan ide yang baik untuk mendapatkan dan menghasilkan karya atau foto yang bagus.

Pada dasarnya, Instagram dapat juga menjadi sarana komunikasi, baik secara persoal maupun kelompok atau massa. Jay Black dan Frederik C. Whitney 1988 mendefinisikan komunikasi massa sebagai sebuah proses di mana pesan-pesan yang diproduksi secara massal disebarkan kepada massa penerima pesan yang luas, tak dikenal dan beragam (Nurudin, 2009:12). Menurut Bittner jenis komunikasi ini adalah mengkomunikasikan pesan kepada sejumlah orang yang dilakukan melalui media massa (Riswandi, 2009, Mulyana, 2007).

Instagram disebut sebagai media sosial, karena kemampuannya dalam membentuk jaringan sehingga memungkinkan banyak orang dapat melakukan interaksi. Karena kemampuannya ini dalam media sosial seseorang dapat melalukan beragam aktivitas dua arah, saling bertukar gagasan, berkolaborasi, dan berkomunikasi secara visual maupun audiovisual (Puntoadi, 2011). Media sosial sebagai "sebuah kelompok aplikasi berbasis internet yang membangun di atas dasar ideologi dan teknologi yang memungkinkan penciptaan dan pertukaran user-generated content" (Kaplan dan Michael, 2010). Selain itu, media sosial merupakan tempat berkumpulnya orang- orang yang ingin berbagi informasi dan tempat untuk mencari teman baru serta berinteraksi dengan teman lainnya secara online (Widyaningrum, 2016).

Media sosial memberikan peluang masuk komunitas yang telah ada sebelumnya dan memberikan kesempatan mendapatkan feedback secara langsung (Puntoadi, 2011). Salah satu media sosial yang sedang banyak digunakan saat ini adalah Instagram, salah satunya dipengaruhi oleh kemampuannya dalam pengunaan gambar dan video (Mahendra, 2017, Handika \& Darma, 2018). Instagram adalah aplikasi layanan berbagi foto yang memungkinkan pengguna untuk berfoto dan memberi filter lalu menyebarluaskannya di jejaring social (Irma, 2017).

Saat ini instagram mengalami eksistensi yang tinggi dan banyak digemari oleh anak muda atau generasi milenial karena instagram digunakan sebagai media untuk mempromosikan hasil foto maupun 
JISIP: Jurnal Ilmu Sosial dan Ilmu Politik

ISSN. 2442-6962

Vol. 9. No. 2 (2020)

sebagai media informasi (Qorib, 2020). Adanya media sosial instagram membuat anak muda semakin kreatif untuk menghasilkan foto yang bagus dan diunggah di akun instagramnya. Keunggulan dari media sosial instagram ini dibandingkan dengan media sosial lain yaitu bisa mengunggah foto lebih cepat dan bisa mengedit foto dengan beraneka macam efek yang diinginkan serta foto tersebut bisa dibagikan ke media sosial lain yang dimiliki. Instagram dapat digunakan sebagai tempat untuk menyalurkan hasil fotografi.

Fenomena fotografi dimulai dari minat mengambil foto sehingga menimbulkan hobi, dimana hobi tersebut dilakukan terus-menerus sehingga menghasilkan foto yang bagus dan bisa dikembangkan menjadi sebuah usaha, minat fotografi didukung oleh berbagai media sosial seperti instagram sehingga fotografer dengan mudah mempromosikan hasil karyanya. Sebuah foto menggambarkan peristiwa baik kejadian sehari-hari, fenomena alam, momen spesial dan hal lain yang berkesan, menciptakan seni fotografi kerakyatan membaur dalam kehidupan sehari-hari dan bisa dinikmati oleh siapa pun (Dimyati, 2010).

Agar dapat dinikmati, karya fotografi harus dipublikasi. Yang dimaksud adalah menyampaikan hasil karya tersebut kepada masyarakat, baik menerbitkannya melalui media cetak, elektronik maupun secara online. Publikasi fotografi yaitu menyampaikan informasi kepada masyarakat dalam bentuk gambar atau visual yang merupakan hasil foto seseorang atau kelompok. Hasil fotografi seseorang atau kelompok saat ini banyak dipublikasikan di media sosial instagram karena instagram saat ini memiliki eksistensi yang tinggi dan digemari oleh kalangan anak muda dan tujuan dipublikasikan hasil fotografi yaitu untuk informasi, promosi maupun bisnis. Ini dilakukan agar masyarakat atau pengguna media sosial instagram bisa mengetahui karya yang dihasilkan melalui sebuah foto.

Penelitian ini menggunakan pendekatan Uses and Gratifications, yang bertujuan untuk untuk menjelaskan proses penerimaan dan penggunaaan media massa. Teori Uses and Gratifications dikenalkan Herbert Blumer dan Elihu Katz pada tahun 1974 (Effendy, 2013). Model uses and gratification menunjukan bahwa yang menjadi permasalahan utama bukanlah bagaimana media mengubah sikap dan peribadi khalayak, tetapi bagaimana memenuhi kebutuhan pribadi dan sosialisasi khalayak. Jadi bobotnya ialah pada khalayak yang aktif, yang sengaja menggunakan media untuk mencapai tujuan khusus (Effendy, 2013).

Teori uses and gratifications menekankan bahwa pengguna media memainkan peran aktif untuk memilih dan menggunakan media tersebut. Pengguna media adalah pihak yang aktif dalam proses komunikasi, pengguna media berusaha untuk mencari sumber media yang paling baik di dalam usaha memenuhi kebutuhannya. Teori ini berasumsi bahwa khalayak memiliki pilihan alternatif dalam upaya memuaskan kebutuhan mereka (Nurudin, 2009).

\section{Metode Penelitian}

Penelitian ini dilakukan dengan metode deskriptif kualitatif. Sugiyono (2015) mendefinisikan metode ini sebagai metode yang melandaskan penelitian pada filsafat postpositivisme. Yang menjadi kunci utama dalam penelitian model seperti ini adalah peneliti itu sendiri. Sampel data penelitian ini diambil menggunakan teknik purposive dan snowbaal sampling.

Penelitian ini berlokasi di Universitas Tribhuwana Tunggadewi Malang pada tanggal 1 Agustus 2020 - 31 Agustus 2020. Alasan memilih lokasi penelitian di Universitas Tribhuwana Tunggadewi 
JISIP: Jurnal Ilmu Sosial dan Ilmu Politik

ISSN. 2442-6962

Vol. 9. No. 2 (2020)

karena UKM X-Flash ini berada di internal Universitas Tribhuwana Tunggadewi Malang dimana UKM X-Flash bergerak dalam bidang fotografi yang memiliki prestasi juga menghasilkan foto bagus.

Selanjutnya data dikumpulkan dengan tiga cara, yaitu observasi, wawancara, dan dokumentsi. Sedangkan teknik analisis data yang digunakan adalah reduksi data, penyajian data dan penarikan kesimpulan. Keabsahan data diuji dengan metode uji kredibilitas dan untuk menguji kredibilitas atau tingkat kepercayaan data digunakanlah triangulasi. Triangulasi merupakan pengecekan data dari berbagai sumber dengan berbagai cara, dan berbagai waktu (Sugiyono, 2015).

\section{Hasil dan Pembahasan}

Pada jaman modern sekarang ini, internet dan penggunaan media sosial sudah termasuk dalam salah satu kebutuhan pokok, dimana sebagian besar orang sudah memiliki ketergantungan terhadap media sosial dan internet yang kadang-kadang dunia maya dianggap sebagai dunia nyata. Instagram merupakan salah satu media sosial yang sedang digemari saat ini, karena memiliki fitur-fitur menarik. Fitur-fitur tersebut menjadikan setiap postingan foto ataupun video menjadi lebih menarik. Hal tersebut dimanfaatkan oleh UKM X-Flash untuk memanfaatkan media sosial instagram sebagai media pendukung berjalan dan berkembangnya UKM tersebut.

Akun media sosial instagram memiliki peran yang cukup penting dalam mendukung perkembangan UKM X-Flash, termasuk peran media sosial instagram terhadap aktivitas publikasi hasil fotografi UKM X-Flash. Akun instagram dimanfaatkan sebagai media publikasi dan promosi untuk meningkatkan popularitas. UKM X-Flash yang menggunakan instagram sebagai media promosi dan publikasi hasil karya fotografi anggota dan kegiatan yang diadakan baik yang bersifat internal maupun eksternal yang diikuti oleh UKM X-Flash. Publikasi pada akun instagram tersebut dapat dikatakan cukup berhasil karena meningkatkan jumlah pengikut dan jumlah like pada postingan di akun instagram UKM X-Flash. Misalnya pada postingan pertama UKM X-Flash pada 23 April 2015 dengan jumlah likes sebanyak 18 pada foto anggota UKM X-Flash angkatan ke-10 dan postingan terakhir pada 22 November 2019 dengan jumlah likes sebanyak 98 pada foto kegiatan Orpis (Orientasi Pendidikan Dasar) UKM XFlash.

Dengan menggunakan akun media sosial instagram UKM X-Flash ingin menunjukkan bahwa pada kampus Unitri terdapat Unit Kegiatan Mahasiswa yang berkumpul dengan hobby yang sama yaitu fotografi. Akun media sosial instagram juga membantu UKM X-Flash untuk memperkenalkan UKM XFlash kepada komunitas fotografi di luar kampus (lingkungan eksternal), baik memperkenalkan setiap kegiatan yang akan diikuti atau yang telah diikuti, dan juga memperkenalkan dan mempublikasikan hasil fotografi anggotanya agar mampu dinikmati oleh khalayak pengguna instagram. Pernyataan diatas didukung dengan adanya postingan yang diposting pada tanggal 14 September 2019 yang beisi tentang kegiatan Probinmaba 2019 yaitu kegiatan tahunan BEM Unitri untuk membina mahasiswa baru dimana pada postingan tersebut UKM X-Flash membantu untuk mempublikasikannya dan dalam kegiatan Probinmaba tersebut UKM X-Flash berperan sebagai media partner. Hal tersebut menunjukkan bahwa UKM X-Flash telah diakui keberadaannya di kampus Unitri. Tidak hanya di kampus Unitri, UKM XFlash juga memposting kegiatan Jambore Fotografi Indonesia XI Jember yang diposting pada tanggal 3 September 2018 dan juga kegiatan Bromo Marathon, hal tersebut membuktikan bahwa UKM X-Flash juga telah dikenal di luar lingkungan kampus Unitri.

www.publikasi.unitri.ac.id 
JISIP: Jurnal Ilmu Sosial dan Ilmu Politik

ISSN. 2442-6962

Vol. 9. No. 2 (2020)

Melalui akun Intagram, UKM X-Flash dapat memberikan atau menerima undangan online dari komunitas seni atau fotografi dari eksternal atau luar kampus. Akun instagram tidak hanya dipakai sebagai media publikasi tetapi UKM X-Flash juga memanfaatkan akun instagramnya untuk berkomunikasi dengan komunitas fotografi di luar kampus. Misalnya saling bertukar informasi seputar kegiatan yang akan digelar oleh UKM X-Flash ataupun oleh komunitas fotografi lain. Hal tersebut terlihat pada salah satu postingan yang ditandai oleh akun instagram @Forkomfm (Forum Komunikasi Mahasiswa Fotografi Malang) yang diposting pada tanggal 28 Maret 2019. Pada postingan tersebut menjelaskan tentang pameran fotografi yang mengajak UKM X-Flash untuk bergabung dan ikut meramaikan acara tersebut. Masih banyak kegiatan eksternal lainnya yang ditandai ke akun instagram UKM X-Flash agar dapat dimanfaatkan sebagai informasi bahwa kegiatan tersebut akan diadakan.

Selain daripada itu, melalui media ini UKM X-Flash juga dapat mengenalkan hasil karya milik anggota kepada khalayak. Hal tersebut tidak hanya terlihat pada postingan yang me-repost hasil karya foto anggotanya tetapi publikasi tersebut juga terlihat dari postingan anggotanya yang menandai akun instagram UKM X-Flash yang jumlahnya lumayan banyak yaitu kurang lebih 164 postingan, pada postingan tersebut terlihat bahwa banyak anggota yang berusaha untuk menunjukkan hasil fotografinya melalui akun instagram masing-masing.

Foto-foto hasil karya anggota UKM X-Flash dipublikasi agar diketahui oleh berbagai kalangan terutama mereka yang menyukai seni fotografi. Dalam publikasi karya foto di instagram, UKM X-Flash memiliki cara untuk meningkatkan kreativitas anggota agar lebih banyak lagi menghasilkan karya. Pertama, UKM X-Flash melakukan hunting bersama para anggota. Hunting bersama para anggota dan DPO serta alumni dilakukan agar anggota tetap memiliki karya dan tidak memiliki karya yang hanya begitu-begitu saja serta menambah pengalaman dan pengetahuan untuk anggota baru dalam bidang fotografi. Untuk melakukan hunting ini juga ada namanya hunting besar dengan menentukan tema.

Kedua, mengunggah kembali (repost) karya anggota di akun instagram UKM X-Flash. Mengunggah kembali karya anggota dilakukan agar instagram UKM X-Flash tidak terlihat kosong atau tetap aktif dalam mempublikasikan hasil fotografi dan juga merepost foto anggota di feed instagram UKM X-Flash agar anggotanya lebih semangat untuk menghasilkan karya-karya untuk dipublikasikan. Karya yang direpost ini adalah hasil foto yang menarik dan juga kreatif dimana ada postingan foto yang dihasilkan dengan alat yang sederhana yaitu kamera lubang jarum dimana hanya menggunakan kaleng rokok yang di cat hitam dan ditengahnya dilubangi sebesar lubang jarum kemudian menggunakan kertas elumen, untuk pencahayaan jika siang hari waktu untuk pengambilan gambar itu 4-5 menit. Hasilnya nanti masih negatif yang kemudian di edit menggunakan photoshop lalu di scan. Adapun karya kreatif lainnya seperti foto still life dimana foto benda mati dibuat seolah-olah hidup dan memiliki makna.

Ketiga, melalukan sharing bersama semua anggota. Adapun sharing bersama di mana semua anggota berkumpul baik anggota muda sampai senior-senior UKM X-Flash, dalam melakukan sharing ini senior-senior akan memberitahu kepada anggota muda tentang bagaimana cara untuk menghasilkan foto yang bagus, memberi saran terkait karya-karya mereka baik karya yang sudah ada maupun yang akan dihasilkan nantinya. Ini dilakukan agar anggota tetap semangat dan tidak pesimis dalam menghasilkan karya untuk dipublikasikan baik di akun instagram pribadi maupun di tag ke akun instagram UKM XFlash. 
JISIP: Jurnal Ilmu Sosial dan Ilmu Politik

ISSN. 2442-6962

Vol. 9. No. 2 (2020)

Keempat, mengadakan pameran. Dalam mengadakan pameran ada pameran yang dilakukan khusus untuk menampilkan karya-karya anggota muda UKM X-Flash sesuai dengan tema yang ditentukan, ini dilakukan agar karya anggota UKM X-Flash bisa dilihat dan diketahui orang-orang luar serta anggota UKM X-Flash sendiri lebih giat dan semangat untuk mencari dan menghasilkan karya foto terbaru dan menarik untuk ditampilkan dan dilihat orang serta pengguna media sosial instagram yang mengikuti instagram pribadi maupun instagram UKM X-Flash. Untuk pameran ini juga UKM X-Flash mengundang UKM-UKM fotografi dari kampus lain untuk hadir melihat pameran tersebut.

UKM X-Flash mengunggah hasil foto atau video dan informasi kegiatan pada akun instagramnya, dapat dijelaskan bahwa lumayan aktif untuk mempublikasikan hasil foto atau video dan informasi kegiatan dari UKMnya ataupun informasi kegiatan yang berasal dari luar kampus. Hal itu terlihat dari lamanya waktu posting antara satu postingan dengan postingan lain yaitu satu hari dan paling lama sampai satu bulan. Jenis postingan yang dipublikasikan pada akun instagram UKM X-Flash yaitu berupa informasi kegiatan baik dari UKM X-Flash maupun kegiatan dari luar kampus, hasil karya anggota UKM $\mathrm{X}$-Flash berupa video ataupun foto, promosi layanan paket photo studio wisuda yang disediakan oleh UKM X-Flash dan juga pamflet event kampus yang menggandeng UKM X-Flash sebagai media partner dalam event tersebut. Berikut adalah bentuk-bentuk postingan pada akun instagram UKM X-Flash:

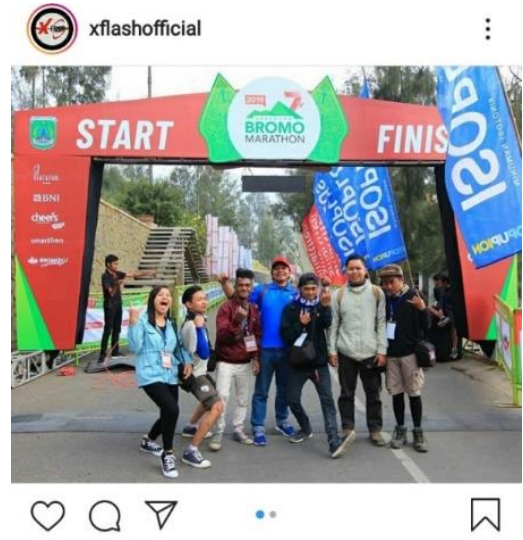

Gambar 1. Kegiatan X-Flash yang dilaksanakan di luar kampus Sumber : Dokumen X-Flash

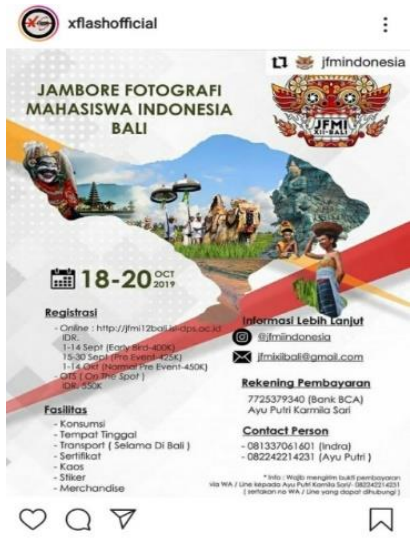

Gambar 2. Kegiatan X-Flash yang dilaksanakan di luar kampus Sumber : Dokumen X-Flash 
JISIP: Jurnal Ilmu Sosial dan Ilmu Politik

ISSN. 2442-6962

Vol. 9. No. 2 (2020)

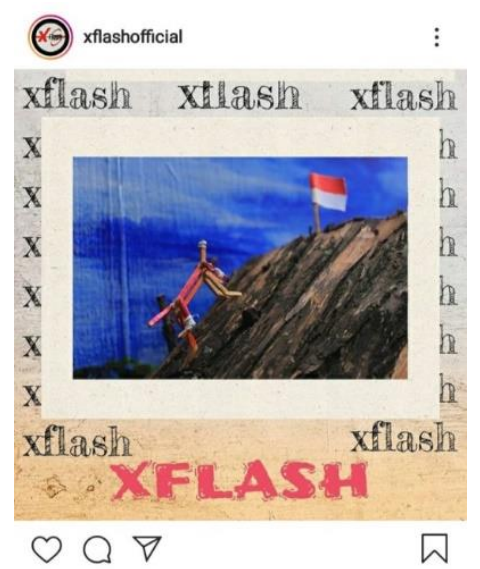

Gambar 3. Hasil karya fotografi UKM

$\mathrm{X}$-Flash dan promosi paket foto wisuda Sumber : Dokumen X-Flash

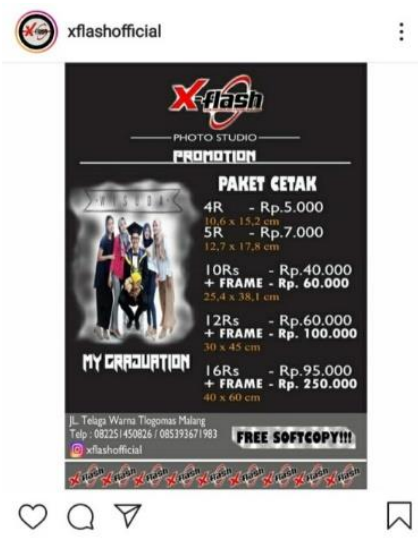

Gambar 4. Hasil karya fotografi UKM X-

Flash dan promosi paket foto wisuda

Sumber : Dokumen X-Flash

Dengan demikian, dapat dijelaskan bahwa UKM X-Flash menggunakan instagram untuk mempublikasikan hasil karya fotografi anggotanya pada akun instagram UKM X-Flash itu sendiri. Tidak hanya itu, instagram juga digunakan sebagai media untuk mempromosikan tentang UKM X-Flash kepada pengikutnya (followers) sehingga UKM X-Flash semakin dikenal bukan hanya di dalam lingkup kampus UNITRI dimana UKM X-Flash berada tetapi juga dikenal di luar kampus. Postingan-postingan pada akun instagram UKM X-Flash juga bisa dikatakan sering untuk memberikan informasi tentang apa yang dilakukan oleh UKM X-Flash agar menarik perhatian pengikutnya (followers) serta tetap eksis.

Dalam teori Uses and Gratifications ini terdapat 4 model yaitu Anteseden, Motif, Penggunaan Media dan Efek. Anteseden meliputi variabel individual dan variabel lingkungan dan berdasarkan hasil wawancara dapat dijelaskan bahwa UKM X-Flash ini memliki variabel individual yaitu data demogarfis dimana data demografis yang dimiliki UKM X-Flash adalah struktur kepengurusan dan juga keanggotaan yang ada di dalam UKM X-Flash ini dimana dengan jelas tercatat ada 94 anggota dari UKM X-Flash baik itu pengurus, anggota muda dan anggota baru. Adapun variabel lingkungan dimana variabel lingkungan ini seperti organisasi, sistem sosial dan struktur sosial, UKM X-Flash ini bisa dikatakan sebagai suatu organisasi karena memiliki suatu tujuan untuk dicapai bersama. Sistem sosial dalam UKM F-Flash sendiri terdapat status sosial ekonomi, ras, budaya dan agama yang berbeda sedangkan untuk struktur sosialnya tidak ada karena struktur sosial itu lebih ke dalam lingkup masyarakat.

Untuk motif sendiri ada tiga orientasi menurut Blumer yaitu kognitif, diversi dan identitas personal. Kognitif artinya kebutuhan informasi, surveillance, atau eksplorasi realitas dan berdasarkan hasil wawancara UKM X-Flash membutuhkan informasi dan dengan menggunakan media sosial instagram membuat UKM X-Flash dengan cepat mendapatkan informasi yang dibutuhkan seperti kegiatan-kegiatan yang akan dilaksanakan, juga kebutuhan informasi akan sesuatu yang berkaitan dengan dunia fotografi.

Selain motif, berdasarkan hasil wawancara, UKM X-Flash menggunakan media sosial instagram sejak tahun 2015 dan dilihat dari akun instagram UKM X-Flash postingan dari bulan April 2015 sampai bulan Februari 2020 ini terdapat 327 postingan. Postingan yang ada di akun instagram UKM X-Flash adalah hasil karya fotografi anggota yang direpost, kegiatan yang dilaksanakan dan yang diikuti oleh UKM X-Flash serta ada juga promosi. Untuk durasi waktu dalam memposting karya atau kegiatan UKM 
JISIP: Jurnal Ilmu Sosial dan Ilmu Politik

ISSN. 2442-6962

Vol. 9. No. 2 (2020)

X-Flash dilihat dari akun instagram yang digunakan di tahun 2015 durasi postingan satu dengan postingan lainnya itu paling lama 27 hari dan paling cepat itu 1 hari sedangkan di bulan Mei, Oktober dan November tidak ada postingan sama sekali. Di tahun 2016 durasi postingannya paling lama 1 bulan dan paling cepat 1 hari sedangkan di bulan Januari, Februari dan Agustus tidak ada postingan sama sekali. Di tahun 2017 durasi postingan paling lama 1 bulan lebih dan paling cepat 1 hari sedangkan di bulan Februari tidak ada postingan sama sekali. Tahun 2018 durasi postingan paling lama 28 hari dan paling cepat 1 hari sedangkan di bulan Januari, Februari, Maret, Juni dan Juli tidak ada postingan sama sekali. Tahun 2019 durasi postingan paling lama 1 bulan lebih dan paling cepat 1 hari. Tahun 2020 durasi postingan paling lama 12 hari dan paling cepat 2 hari.

Selanjutnya ada efek dimana media memberikan kepuasan untuk pengguna dan berdasarkan hasil wawancara, efek yang didapat UKM X-Flash dalam mengggunakan media sosial instagram yaitu mendapatkan informasi yang dibutuhkan dalam dunia fotografi, berinteraksi dengan kerabat atau UKM fotografi lainnya dengan cepat, tempat untuk menampilkan hasil karya anggota serta kegiatan dan juga memperkenalkan UKM X-Flash di luar lingkup kampus Unitri tempat UKM X-Flash berada.

\section{Kesimpulan}

Akun instagram @xflashofficial memiliki banyak peran yaitu selain sebagai media publikasi dan promosi yang digunakan untuk meningkatkan popularitas, akun instagram tersebut juga dimanfaatkan untuk meningkatkan eksistensi UKM X-Flash agar dapat dikenal di luar kampus dan juga lingkup kampus UNITRI sendiri. Peran lainnya yaitu dengan akun instagram tersebut UKM X-Flash dapat memberikan atau menerima undangan online dari komunitas seni atau fotografi eksternal atau luar kampus, tidak hanya itu akun instagram UKM X-Flash juga dapat memperkenalkan hasil karya fotografi UKM X-Flash kepada khalayak.

Adapun cara UKM X-Flash mendukung kreativitas anggota untuk tetap menghasilkan karya fotografi yaitu dengan melakukan hunting bersama para anggota UKM X-Flash, merepost karya anggota di akun instagram UKM X-Flash, melakukan sharing dimana membahas serta memberikan saran terkait karya anggota agar tetap menghasilkan karya, adapun UKM X-Flash ini mengadakan pameran untuk menampilkan hasil karya anggota agar diketahui oleh orang bukan hanya di media sosial instagram tetapi bisa melihatnya secara langsung dalam pameran tersebut.

\section{Daftar Pustaka}

Dimyati, M. (2010). Cara Meningkatkan Minat Gotong Royong Masyarakat. Jakarta: Rajagrafindo Persada.

Effendy, Uchjana. 2013. Komunikasi Teori dan Praktik. Bandung: Remaja Rosdakarya.

Handika, Made Resta \& Darma, Gede Sri. 2018. Strategi Pemasaran Bisnis Kuliner Menggunakan Influencer Melalui Media Sosial Instagram. Jurnal Manajemen dan Bisnis, Volume 15, No. 2, hal. 192-203.

Irma, Ade, 2017, Peran Instagram Sebagai Media Komunikasi Pemasaran Bisnis Online (Studi Deskriptif Kualitatif Pada Bisnis Online Beautyhomeshop). Jurnal Online Kinesik, Vol. 4 No. 2, hal. 1-12.

Kaplan, Andres \& HaenLein, Michael. 2010. User Of The World, Unite! The Challenges and Opportunities Of Social Media. Business Horizons.

Mahendra, Bimo. 2017. Eksistensi Sosial Remaja Dalam Instagram (Sebuah Perspektif Komunikasi). Jurnal Visi Komunikasi, Volume 16, No.01, hal. 151-160.

www.publikasi.unitri.ac.id 
JISIP: Jurnal Ilmu Sosial dan Ilmu Politik

ISSN. 2442-6962

Vol. 9. No. 2 (2020)

Mulyana, Deddy. 2007. Ilmu Komunikasi: Suatu Pengantar. Bandung : Remaja Rosdakarya.

Nurudin. 2009. Pengantar Komunikasi Massa. Jakarta: Rajawali Pers.

Puntoadi, Danis. 2011. Meningkatkan penjualan melalui media sosial. Jakarta: PT. Gramedia Pustaka Utama.

Qorib, Fathul. 2020. Pola Konsumsi Media pada Generasi Milenial Kota Malang. Jurnal Ilmu Komunikasi : Ultimacomm. Vol 12 No 1 hal 53-71.

Riswandi. 2009. Ilmu komunikasi. Jakarta: Graha Ilmu.

Sugiyono. 2011. Metode Penelitian Kuantitatif, Kualitatif dan R\&D. Bandung: Alfabeta.

Widyaningrum, Premi Wahyu. 2016. Peran Media Sosial sebagai Strategi Pemasaran pada Sewa Kostum Meiyu Aiko Malang. Jurnal Al Tijarah, Vol. 2, No. 2, hal. 230-257. 